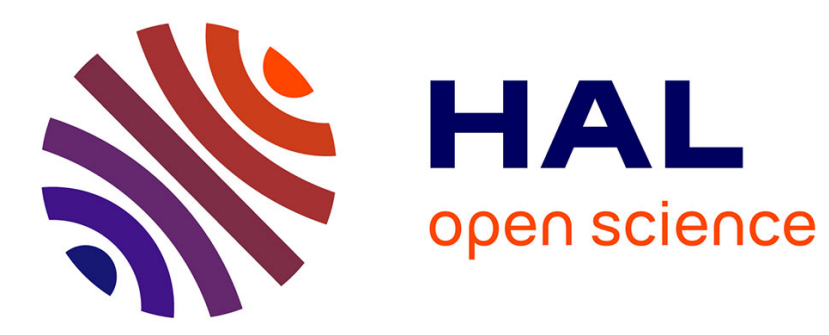

\title{
Optical Feedback Interferometry for Raster Scan Profilometry
}

\author{
Bastien Grimaldi, Antonio Luna Arriaga, Francis Bony, Clément Tronche,
} Julien Perchoux

\section{- To cite this version:}

Bastien Grimaldi, Antonio Luna Arriaga, Francis Bony, Clément Tronche, Julien Perchoux. Optical Feedback Interferometry for Raster Scan Profilometry. IEEE Sensors 2017, Oct 2017, Glasgow, United Kingdom. 3p. hal-01685167

\section{HAL Id: hal-01685167 https://hal.science/hal-01685167}

Submitted on 16 Jan 2018

HAL is a multi-disciplinary open access archive for the deposit and dissemination of scientific research documents, whether they are published or not. The documents may come from teaching and research institutions in France or abroad, or from public or private research centers.
L'archive ouverte pluridisciplinaire HAL, est destinée au dépôt et à la diffusion de documents scientifiques de niveau recherche, publiés ou non, émanant des établissements d'enseignement et de recherche français ou étrangers, des laboratoires publics ou privés. 


\title{
Optical Feedback Interferometry for Raster Scan Profilometry
}

\author{
Bastien Grimaldi ${ }^{1}$, Antonio Luna Arriaga ${ }^{1}$, Francis Bony ${ }^{1}$, Clement Tronche ${ }^{1}$ and Julien Perchoux ${ }^{1}$ \\ ${ }^{1}$ LAAS-CNRS, Université de Toulouse, CNRS, INPT, Toulouse, France \\ julien.perchoux@laas.fr
}

\begin{abstract}
This paper evaluates optical feedback interferometry for raster scan profilometry applications. It is shown both experimentally and theoretically that the spot size on target plays a major role as the phase distribution of the scattering contributions impacts drastically the sensor signal.
\end{abstract}

Keywords-Laser sensor; profilometry; optical feedback interferometry

\section{INTRODUCTION}

Optical feedback interferometry (OFI) is known for enabling the development of low-cost metrological sensors due to its self-aligned and compact setup. OFI occurs when a laser beam points onto a moving target and part of the beam is backscattered into the laser cavity producing an interference with the cavity electric field. These interferences induce variations of the laser power which are collected through a photodetector (PD), thus the basic sensing scheme consists of a laser diode (LD), a PD, a focusing lens and the electronics to recover the sensing signal [1].

Perhaps the most consolidated applications of the OFI sensing scheme are the are vibration, absolute distance and velocity measurement over solid targets. Just like in conventional interferometry, OFI has been signaled to be useful in profilometry applications. The maximum measurable step height is limited to $\lambda_{2}$ due to OFI's phase ambiguity above this value. By using a dual-wavelength fiber ring laser setup, Ma et al [2] leveraged this restriction to half the synthetic wavelength of the two selected wavelengths and presented a step height measurement of $1 \mathrm{~mm}$. Imaging applications have been shown by using mid-infrared $(\lambda=3.57 \mu \mathrm{m})$ [3] and terahertz [4] interband cascade laser. These configurations require either mechanical or electronic modulation over OFI signal.

If OFI's intrinsic features of simplicity and low-cost want to be preserved, the basic sensing scheme must be privileged. To the best of our knowledge, in this context most of the literature exploits the amplitude variations of the temporal OFI signal resulting of variations in reflectivity or defocus amount in a dot-by-dot acquisition approach (e.g. [5]).

The principle of performing raster scan surface profilometry in analogy to conventional vibration measurement is depicted in Fig.1. From OFI theory, an interferometric fringe is generated when the laser-target distance changes from half a wavelength of the laser electromagnetic field. In the case of displacement sensing, this happens as the target moves of half wavelength along the optical path (Fig.1(A)). At a first sight, if the setup moves transversely (Fig.1(B)), the resulting optical
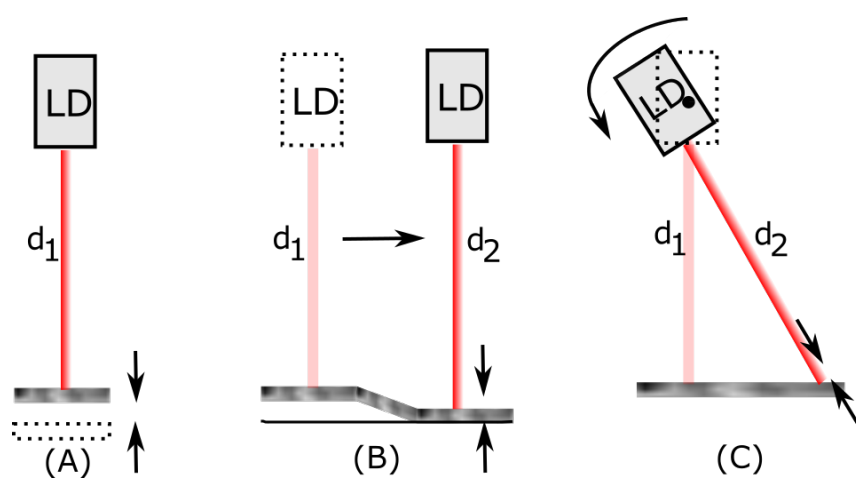

Fig. 1: Comparison between the conventional configuration for OFI vibration measurement (A) and two configurations to perform raster scan profilometry (B) and (C).

path variations are expected to generate an equivalent number of fringes like in vibrometry configuration. Same behavior shall be observed when the LD is tilted from an initial position by a small angle (Fig.1(C)). However, as explained in [6] due to the roughness of the surface, "the scattered fields from every point illuminated by the light beam add with markedly different phases, resulting in an interference pattern known as speckles".

Instead on further trying to exploit this phenomenon like the work in [7] where different roughness levels of a same material can be identified. In this work we perform a simulation and an experimental setup to expose the compromise between the spot size of the measuring beam and the micro-geometry of the target surface.

\section{ADDITIVE PHASES MODEL}

As demonstrated in [8], it is possible to perform a numerical simulation on the behavior of slightly phase-shifted OFI signals by summing up an independent number of optical output power variations. Therefore, the addition of $N$ contributive signals can be expressed as:

$$
P=\sum_{k=1}^{N} \frac{P_{\max } m(\theta)}{N} \cos \left[\frac{2 \pi}{\lambda} \delta(\theta, k)+\phi_{0}\right]
$$

where $P$ is the integrated power over the PD surface. $P_{\max }$ is the power amplitude of the $k$ th signal impacted by the modulation coefficient $m(\theta)$, with $\theta$ being the incident angle. $\lambda$ is the LD's wavelength, $\delta(\theta, k)$ is the path difference between 


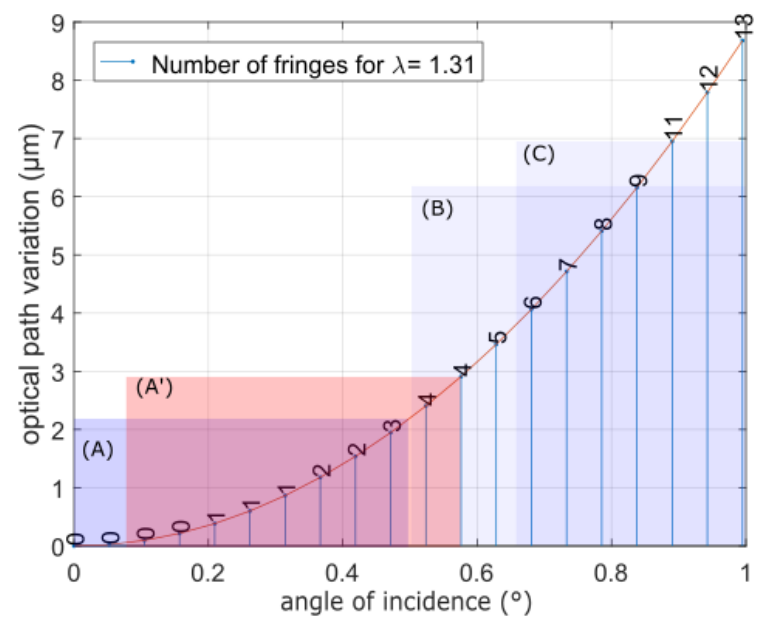

Fig. 2: Calculation of the expected number of fringes as a function of the tilt angle.

the initial and the reflected light for each ray and $\phi_{0}$ is the initial phase.

\section{A. Simulation example}

Raster scan configuration as depicted in Fig.1(C) allows to modify the distance between the target and the LD $\left(d_{1}\right)$ with high accuracy. When a LD perpendicular to a flat surface is tilted by a controlled angle, the variations of the external cavity $\left(d_{2}-d_{1}\right)$ can be easily calculated. Setting the distance $d_{1}$ to 57 $\mathrm{mm}$, the theoretical curve of optical path variations and the expected number of generated fringes have been calculated in Fig.2. The four different shaded regions represent the range of tilts that will be addressed on the experimental section.

Figure 3 shows the simulation result whith $\lambda=1.31 \mu \mathrm{m}$ and a spot size of $60 \mu \mathrm{m}$. The calculated OFI signal is generated while taking into consideration 10000 phase-shifted backscattered contributions distributed over the laser spot on target and the associated optical path variation $\delta(\theta, k)$ as depicted in Fig. 2 for a movement from $d_{1}$ to $d_{2}$. Conversely to the expected behavior for an infinitely small spot size on target, the fringes in the center corresponding to the addition of larger phase-shifts depict a destructive behavior. While the simulation is performed for a discrete number of signals, the following section shall show this behavior experimentally i.e. where a density of photons is being impacted in dynamic manner.

\section{EXPERIMENTAL SETUP}

To finely control the optical path variations in the experimental setup it was decided to fix the LD and rather deviate the beam by using a rotating mirror. Fig.4 shows: (1) a LD $L 1310 P 5 D F B$ powered in continuous wave at $5 \mathrm{~mW}$ emitting at $\lambda=1.31 \mu \mathrm{m}$, (2) a lens $C 240 T M E-C$ with 8 $\mathrm{mm}$ focal, (3) a variable optical attenuator, (4) a motorized mirror galvanometer GVS002 from Thorlabs and (5) a mirror PF10 - 03 - P01 being the scanned surface.

The GVS002 was powered by a low noise, linear supply (Thorlabs GPS011). According to the datasheet the mirror can be tilted with a repeatability of $0.0008^{\circ}$. A function generator

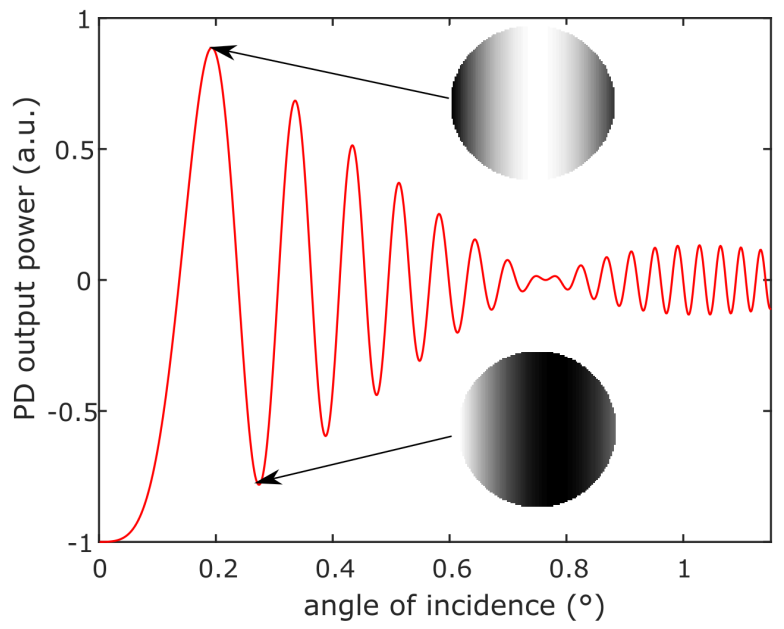

Fig. 3: Simulation of the OFI signal for a rotation of the sensor by $1^{\circ}$ with a laser spot of diameter $60 \mu \mathrm{m}$. The circle plots represent the distribution of phases of the backscattered wave re-entering the laser cavity over the laser spot on the target at two different aperture angles.

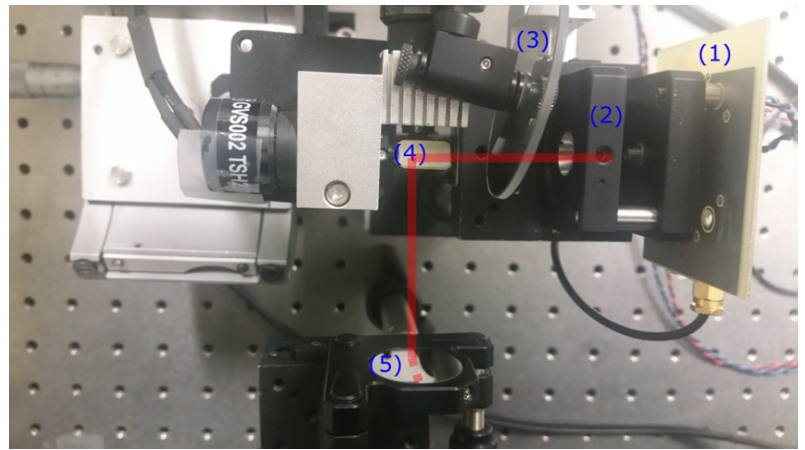

Fig. 4: Photography of the experimental setup (top view). Conventional instrumentation like power supply, function generator and oscilloscope are not represented for sake of clarity.

(SG) was used to drive the mirror with a triangular signal of $250 \mathrm{mVpp}$ at an arbitrary frequency of $50 \mathrm{~Hz}$. Other frequencies and amplitudes were tested to warranty that the observed OFI signal felt within the bandwidth of the LD driver circuit. An oscilloscope was used to record OFI and SG signals. After characterization, it was found that the GVSO02 tilted the mirror of $0.5^{\circ}$ for the induced triangular signal. By adding a bias offset to the amplitude of the triangular signal it was possible to illuminate different segments over the mirror and thus modify the conditions of the raster scan OFI signal. From Fig.2 the depicted regions (A), (A'), (B) and (C), correspond to an offset producing a tilt on the mirror of $0.25^{\circ}, 0.3^{\circ}, 0.75^{\circ}$ and $0.9^{\circ}$ respectively. These four different scan conditions are discussed hereafter.

\section{RESULTS AND DISCUSSION}

The conditions established on region A from Fig.2 are reproduced in Fig.5(a): a ramp signal tilting the mirror from $0^{\circ}$ to $0.5^{\circ}$ produced an optical path variation of $2 \mu \mathrm{m}$. Three fringes were generated in forward direction and symmetrically 
backwards. It can be seen that in these conditions, the number of observable fringes correspond exactly to the change of external cavity length.

Then, the spot size illuminating the scanned mirror was increased by moving the distance of the focusing lens [Fig.4(2)] by about $1 \mathrm{~mm}$. As it can be observed in Fig.5(b), increasing the mirror tilt of $0.05^{\circ}$ impacted the raster scan OFI signal. The four expected fringes are largely corrupted and this behavior does not match with the theoretical vibrometry calculations of region A' from Fig.2. Instead, the observed behavior corresponds to the model presented in Section II. i.e. within the spot size part of the photons interfered in a destructive manner due to the optical path differences induced by the tilt angle.

To verify that the fringes were effectively affected by the relationship between the tilt angle and the spot size, the focal distance was set again to the optimal focus configuration generating the three fringes as shown in Fig.5(a). Thus, the tilt angle on the mirror was further increased reaching a central offset of $0.75^{\circ}$. This configuration correspond to region B of Fig.2. As shown in Fig.5(c), for an optical path variation of 6 $\mu \mathrm{m}$ (from $9 \mu \mathrm{m}$ to $3 \mu \mathrm{m}$ in Y-axis from Fig. 2) there are two missing fringes from the nine expected by a pure vibrometry approach. This OFI signal is less corrupted as compared to Fig.5(b), meaning that it is possible to scan at a bigger angle with a smaller spot size. Finally, Fig.5(d) shows an OFI signal corrupted in a similar manner as in Fig.5(b). This condition was reached by further increasing the offset on the ramp signal driving the mirror as depicted in region $\mathrm{C}$ of Fig. 2 where an optimal laser spot was set.

\section{CONCLUSION}

We have shown the compromise between the spot size and the micro-geometry of a target in order to perform raster scan profilometry using the standard OFI sensing scheme. The height difference of an illuminated area on the target introduces a phase-shift on the OFI signal generating destructive interferences for amplitudes close to $\lambda / 2$. The simulation made by addition of discrete OFI signals agrees well with the experiments performed.

\section{REFERENCES}

[1] T. Taimre, M. Nikolic, K. Bertling, Y. Lim, T. Bosch, and A. Rakic, "Laser feedback interferometry: A tutorial on the self-mixing effect for coherent sensing," Adv. Opt. Photon., vol. 7, pp. 570-631, 2015.

[2] S. Ma, F. Xie, L. Chen, Y. Z. Wang, D. L. L., and K. Q. Zhao, "Development of dual-wavelength fiber ring laser and its application to step-height measurement using self-mixing interferometry," Opt. Express, vol. 24, pp. 5693-5698, 2016.

[3] K. Bertling, T. Taimre, G. Agnew, Y. L. Lim, P. Dean, D. Indjin, S. Hofling, R. Weih, M. Kamp, M. von Edlinger, J. Koeth, and A. D. Rakic, "Simple electrical modulation scheme for laser feedback imaging," IEEE Sensors Journal, vol. 16, pp. 1937-1942, 2016.

[4] P. Dean, Y. L. Lim, A. Valavanis, R. Kliese, M. Nikolic, S. Khanna, M. Lachab, D. Indjin, Z. Ikonic, P. Harrison, A. D. Rakic, E. Linfield, and A. Giles Davies, "Terahertz imaging through self-mixing in a quantum cascade laser," Opt. Lett., vol. 36, pp. 2587-2589, 2011.

[5] J. Ling, J. Ma, and S. Zhuang, "Experimental research on profile measurement based on laser optical feedback," Optik, vol. 124, pp. 17701772, 2013.

[6] S. Ozdemir, S. Shinohara, S. Ito, S. Takamiya, and H. Yoshida, "Compact optical instrument for surface classification using self-mixing interference in a laser diode," Opt. Eng., vol. 40, pp. 38-43, 2001.

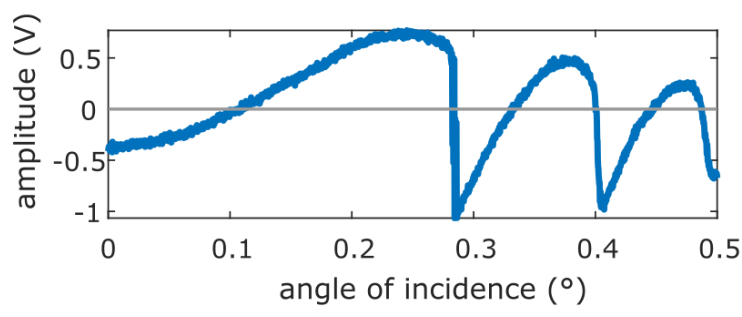

(a) Region A from Fig.2. In this case raster scan behaves as conventional OFI vibrometry.

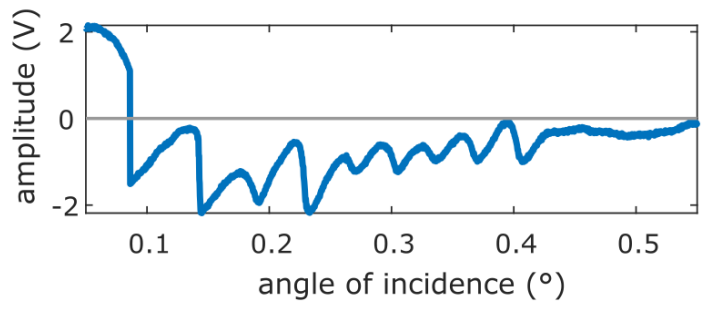

(b) Region A' from Fig.2. Bigger spot size.

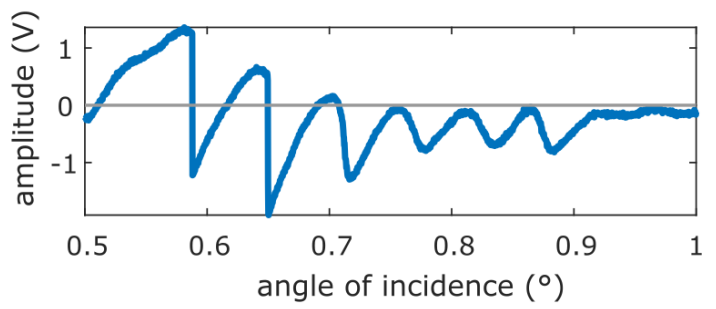

(c) Region B from Fig.2. Spot size like (a) for bigger tilt.

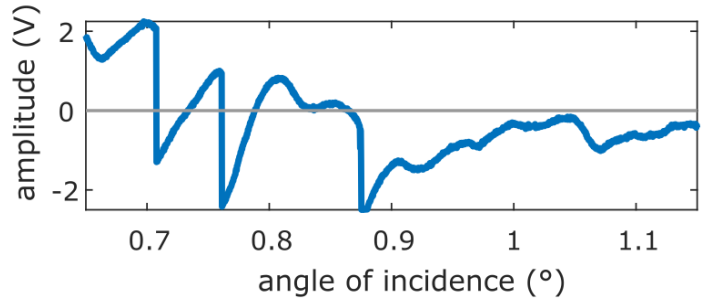

(d) Region C from Fig.2. An increased tilt on the measured surface prevents raster scan to behave as conventional OFI vibrometry.

Fig. 5: Experimental OFI signals for different optical path variations.

[7] J. Herbert, K. Bertling, T. Taimre, A. D. Rakic, and S. Wilson, "Surface roughness characterisation using optical feedback interferometry," Electron. Lett., vol. 53, pp. 268-270, 2017.

[8] Y. Zhao, J. Perchoux, L. Campagnolo, T. Camps, R. Atashkhooei, and V. Bardinal, "Feedback interferometry for microscale-flow sensing study: numerical simulation and experimental validation," Opt Express, vol. 24, pp. $23849-23862,2016$. 